\title{
A Case of Sarcoidosis with Diffuse Cavitary Lesion in the Lung
}

\author{
Akciğerde Yaygın Kaviter Lezyon İzlenen Sarkoidoz Olgusu
}

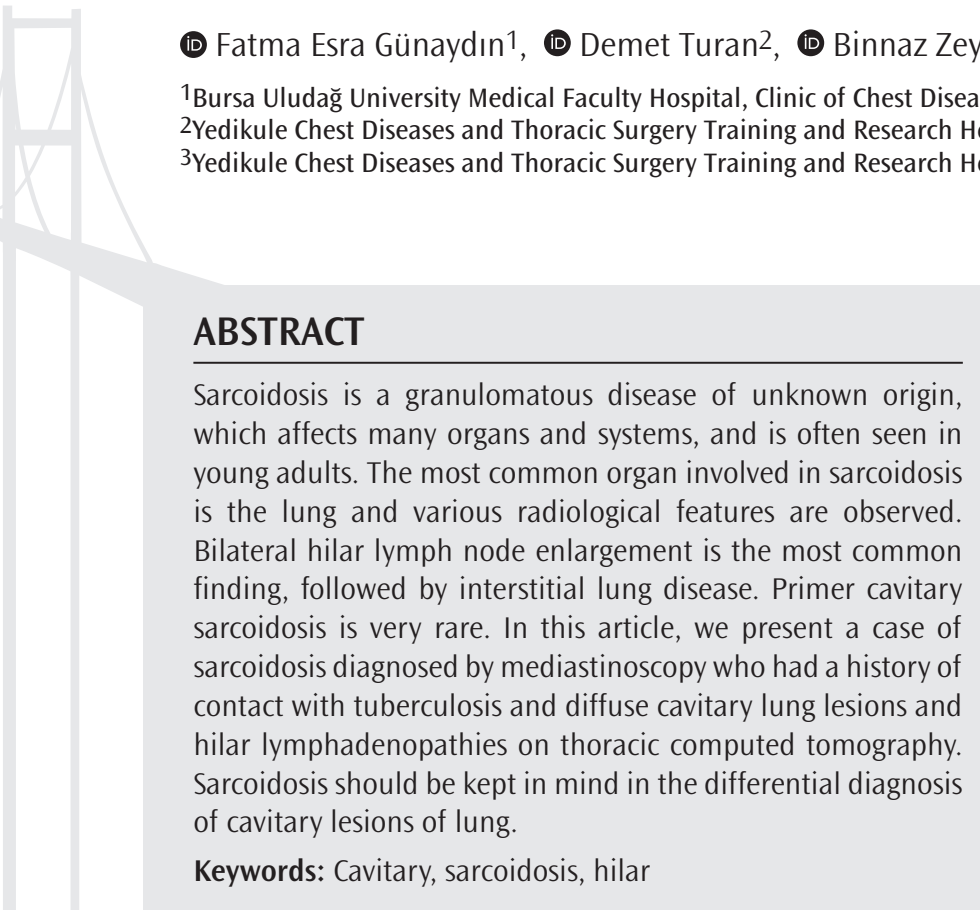

öz

Sarkoidoz, nedeni bilinmeyen, sıklıkla genç erişkenlerde görülen birçok organ ve sistemi etkileyen granülomatöz bir hastalıktır. Sarkoidozda en sık tutulan organ akciğer olup, çeșitli radyolojik görünümler izlenir. Bilateral hiler lenf nodu genișlemesi en sık bulgudur ikinci olarak interstisyel akciğer hastalığı izlenir. Primer kaviter sarkoidoz oldukça nadir izlenmektedir. Bu yazıda, tüberküloz temas öyküsü olan, akciğer bilgisayarlı tomografisinde hiler lenfadenopatileri ve yaygın kaviter lezyonları izlenen mediastinoskopi ile sarkoidoz tanısı konan olgu sunulmuştur. Kaviter lezyonların ayırıcı tanısında sarkoidozu vurgulamak için sunduk.

Anahtar Kelimeler: Kaviter, sarkoidoz, hiler

\section{Introduction}

Sarcoidosis is defined as a granulomatous disease of unknown origin that occurs in young adults, usually affecting many organs and systems such as hilar lymphadenopathy, lung infiltration, eye and skin findings, heart, liver, nervous system, musculoskeletal system, and peripheral lymph nodes. The most commonly involved organ is the lung and is responsible for the morbidity and mortality of the disease. Diagnosis is usually based on clinical, laboratory and radiological findings, including histopathologic findings (epitholoid cell granuloma without caseification) that can be demonstrated in more than one system and exclusion of other causes of granulomatous inflammation (1). Pulmonary tomography may show various radiological involvements (2). Bilateral hilar lymph node enlargement is the most common radiological finding and the second most common pattern is interstitial lung disease. Typical findings in high-resolution computed tomography are perilymphatic micronodules, fibrotic changes and bilateral perihilar opacities. Atypical appearances, mass-like or alveolar opacities, honeycomb cysts, miliary opacities, mosaic attenuation, tracheobronchial involvement, pleural disease, and cavitary involvement are rare (3). Acinar or nodular disease in the lung parenchyma is common in young individuals (4). Primary cavitary sarcoidosis is very rare and observed at a rate of $<0.8 \%$ (5). The cavitation of parenchymal lesions was observed as $10 \%$ in end-stage disease (6). In this article, a case of primary cavitary sarcoidosis is presented with the literature.

\section{Case Report}

A 22-year-old female patient presented to outpatient clinic with complaints of cough and sputum production. She did not have a known history of systemic disease. She had a recent history of oral cefuroxime axetil (2x500 mg) and clarithromycin (2x500 mg) use for 7 days. The patient was a housewife and had no occupational exposure. The patient had a history of tuberculosis contact. On physical examination, respiratory sounds were evaluated as slightly rough. Posteroanterior chest X-ray showed a cavitary appearance in the right lung at the level of fourth rib. 
Complete blood count and biochemistry parameters were evaluated as normal. Purified protein derivative (PPD) test, sputum ARB and routine blood tests were requested. PPD was negative and sputum ARB samples were evaluated as negative five times. Cytoplasmic-anti neutrophil cytoplasmic antibodies, Perinuclear anti-neutrophil cytoplasmic antibodies and antinuclear antibody values were negative. Thoracic computed tomography showed diffuse mediastinal lymphadenopathies, ground glass areas and cavitary lesion in the right apex. Endobronchial Ultrasound (EBUS) was performed and no endobronchial lesion was observed. The sample taken from subcarinal lymphadenopathy was evaluated as fibrotic tissue fragments suspected for granulomatous inflammation. For definitive diagnosis, the patient was evaluated by mediastinoscopy. The results of upper and lower paratracheal lymph nodes were presented as non-necrotizing granulomatous inflammation. Serum ACE level was $72 \mathrm{U} / \mathrm{L}$ and urine calcium level was normal. During the follow-up period, lesions compatible with erythema nodosum developed in the lower extremity of the patient. The patient was evaluated as sarcoidosis and $20 \mathrm{mg}$ oral prednisone was started. Clinical and radiological response was observed. A regression of the cavitary lesion was observed on the posteroanterior radiograph of the patient, complaints reduced and the patient was followed-up. Informed consent was obtained from the patient.

\section{Discussion}

Sarcoidosis is characterized by granulomatous inflammation with lymphadenopathy, pulmonary infiltration and eye and skin lesions. It is more common in young adults and women, and $70 \%$ of patients are young adults between the ages of 20-40 $(7,8)$. The incidence of sarcoidosis in our country has been reported as 4/100.000 (9). Our case was a 22-year-old woman and was included in the population in which the disease is common.

The most common organ involved in sarcoidosis is the lung. Pulmonary involvement occurs in 95\% of all cases (10). Symptoms such as dry cough (30\%), dyspnea (28\%), chest pain (25\%), wheezing and rarely hemoptysis may occur in patients with pulmonary involvement (11). Our case was admitted to the outpatient clinic with complaints of dry cough and sputum production. Due to sputum production, sputum culture and acid-resistant bacteria examination in sputum were requested. ARB was negative for five times and there was no growth in non-specific and tuberculosis cultures.

It should be kept in mind that extra-pulmonary organs and tissues may be affected while taking anamnesis in a patient with sarcoidosis and extra-pulmonary symptoms should be questioned. Extra-pulmonary involvement is usually associated with pulmonary involvement in sarcoidosis (12). Extra-pulmonary involvement is most commonly seen in the liver, spleen, eye, peripheral lymph nodes and skin. Neurological involvement, cardiac involvement, chronic hypercalcemia, chronic uveitis, cystic bone lesions, lupus pernio, nasal mucosa involvement and nephrocalcinosis are extra-pulmonary involvements with poor prognosis. Therefore, diagnosis and treatment of extra-pulmonary involvement is important to reduce morbidity and mortality in sarcoidosis (13). Although there are no symptoms, basal tests (complete blood count, biochemical tests, urinalysis, 24-hour urine calcium, electrocardiography, PPD and eye examination) should be performed to evaluate extra-pulmonary sarcoidosis (12). In our case, complete blood count and biochemistry tests were unremarkable. PPD was evaluated as anergic. Eye examination was normal.

The presence of hypercalcemia is an important finding in supporting the diagnosis of sarcoidosis. It is caused by increased production of 1,25-dihydroxyvitamin D3 from alveolar macrophages due to increased 1-alpha hydroxylase activity. Hypercalciuria is frequently seen due to hypercalcemia $(1,11)$. Serum and urine calcium levels were within normal limits in our patient.

Because sarcoidosis is a systemic, autoimmune, inflammatory disease, laboratory tests demonstrating systemic inflammation are often positive. Elevated sedimentation and CRP levels are common. Chronic disease anemia, Iymphopenia, eosinophilia and thrombocytopenia may be seen. Elevated ACE serum level is an important feature in sarcoidosis and has been reported with a frequency of $40-90 \%(1,11)$. The hemoglobin value, lymphocyte count and eosinophil count were within normal limits in our patient. Serum ACE level was $72 \mathrm{U} / \mathrm{L}$ and it was high. In addition to sarcoidosis, elevation of serum ACE may occur in diseases such as silicosis, human immmunodeficiency virus (HIV) infection, liver cirrhosis, diabetes mellitus, Gaucher's disease, histoplasmosis and aspergillosis. There was no history of occupational or environmental exposure for silicosis. In our case, HIV RNA and anti-HIV were negative, blood glucose levels were within normal limits, liver functions were normal, serum galactomannan was negative and histoplasma antibody was negative.

The diagnosis of sarcoidosis is made by combining clinical, radiological and laboratory findings; however, the gold standard is histopathological diagnosis. The suspicion of sarcoidosis is frequently raised by chest X-ray findings, because $90-95 \%$ of the patients have pathological changes in chest radiographs. The radiological findings of sarcoidosis are quite broad spectrum and bilateral hilar lymph node enlargement is the most common finding, followed by interstitial lung disease. Scadding divided sarcoidosis into four stages according to changes in chest X-ray (12) (Table 1). The posteroanterior chest $X$-ray of our case showed a cavitary appearance of approximately $2 \mathrm{~cm}$ in diameter in the right lung at the level of fourth rib, and the hili were bilaterally wide. Radiologically, it was evaluated as stage 2 .

Typical signs of sarcoidosis in HRCT are perilymphatic micronodules, fibrotic changes, and bilateral perihilar opacities. Atypical appearances, mass-like or alveolar opacities, honeycomb cysts, miliary opacities, mosaic attenuation, tracheobronchial involvement, pleural disease and cavitary involvement are rare (3). Computed tomography of our case revealed diffuse mediastinal lymphadenopathies, ground glass areas

\begin{tabular}{l|l|}
$\begin{array}{l}\text { Table } \mathbf{1} \text {. Scadding staging in sarcoidosis according to chest X-ray } \\
\text { findings }\end{array}$ \\
\hline Stage $\mathbf{0}$ & Normal \\
\hline Stage 1 & Bilateral hilar adenopathy, normal lung parenchyma \\
\hline Stage 2 & Hilar adenopathy with pulmonary infiltration \\
\hline Stage 3 & Pulmonary infiltration without hilar adenopathy \\
\hline Stage 4 & Pulmonary fibrosis \\
\hline
\end{tabular}


and a $2 \times 2.30 \mathrm{~cm}$ diameter cavitary lesion in the right apex. It has been suggested that cavitary lesions may be associated only with sarcoidosis as well as associated diseases, especially aspergilloma (14-16). In the study of Rockhoff and Rohadgi (6), cavitation of parenchymal lesions was observed as $10 \%$ in end-stage disease. In a study by Freundlich et al. (5), it was reported that cavitary lesions were present in $0.6 \%$ of patients with pulmonary sarcoidosis based on chest X-ray, and Mayock et al. (17) reported that cavitary lesions were present in $8.3 \%$ of sarcoidosis patients. The natural course of these lesions is highly variable; they can spontaneously resolve, stabilize or worsen, and their course may result in various complications such as hemoptysis, pneumothorax and aspergilloma (18-20). No pneumothorax, hemoptysis and aspergilloma were observed during the follow-up of our case, and the cavitary lesion regressed under steroid therapy.

Biopsy is required for definitive diagnosis in patients with suspected sarcoidosis by radiological and other laboratory methods. Transbronchial

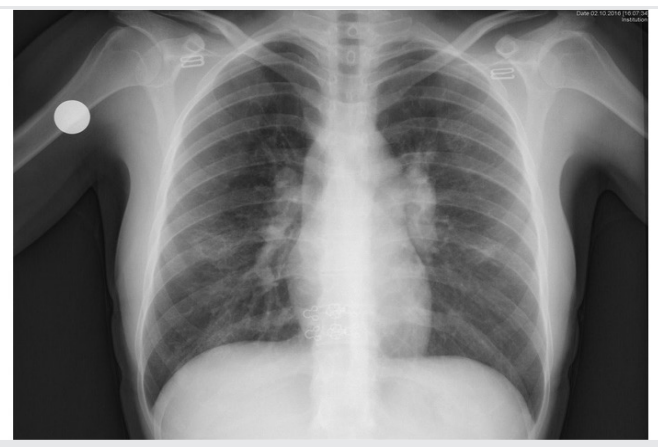

Figure 1. Posteroanterior chest X-ray of the patient

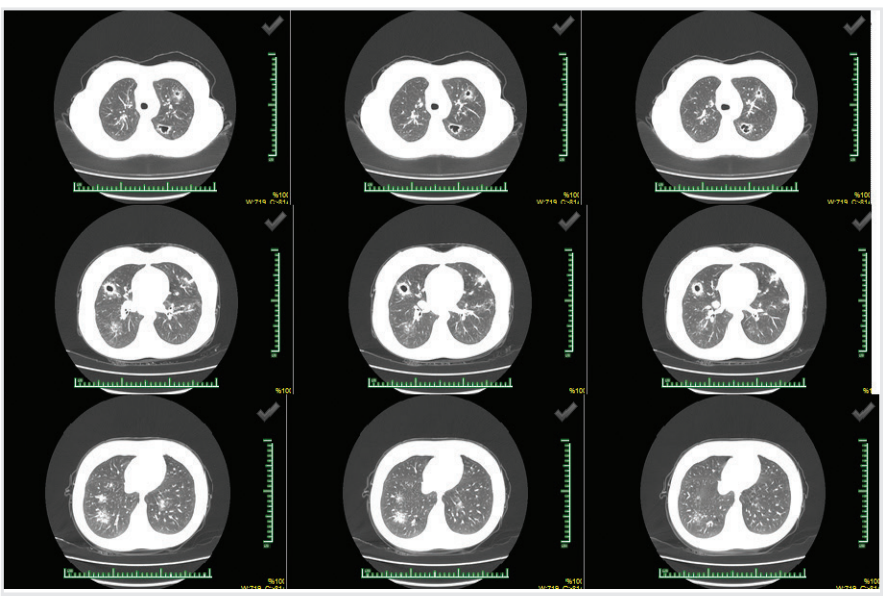

Figure 2. Thorax computed tomography images of the patient
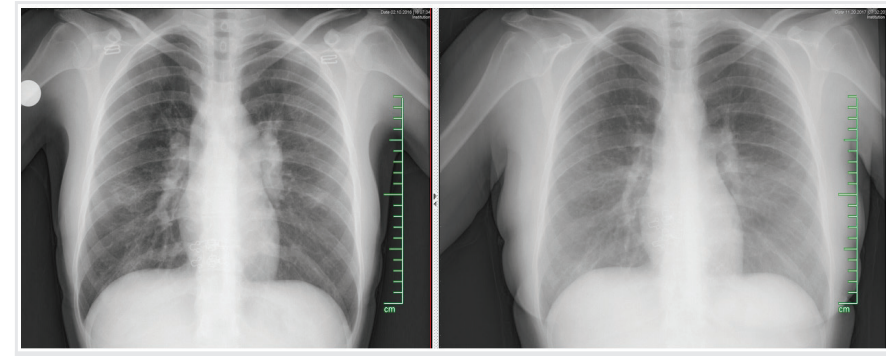

Figure 3. Comparison of posteroanterior X-ray of the patient before and after treatment biopsies play an important role in the histological diagnosis of lung lesions. As another diagnostic method, EBUS has gained importance in recent years. In sarcoidosis, lymph nodes in areas adjacent to the bronchi often enlarge, and they can be reached with EBUS and needle biopsy can be done. However, mediastinoscopy can be performed with general anesthesia and biopsy can be performed from mediastinal lymph nodes in patients who cannot be diagnosed by EBUS. The well-circumscribed epithelioid non-necrotizing granulomas are typical histopathologic findings of sarcoidosis (11). Transbronchial biopsy was evaluated as non-diagnostic and CD4/CD8 ratio was 4 in bronchoalveolar lavage fluid. Because of mediastinal diffuse lymphadenopathies, EBUS was performed and no endobronchial lesion was observed, and the sample taken from subcarinal lym phadenopathy was evaluated as fibrotic tissue fragments suspected for granulomatous inflammation. Mycobacteria Tuberculosis polymerase chain reaction was evaluated as negative in tissue samples. For definitive diagnosis, the patient was evaluated by mediastinoscopy. The results of upper and lower paratracheal lymph nodes were presented as non-necrotizing granulomatous inflammation, and our case was evaluated as sarcoidosis.

There is no consensus on treatment algorithm and the appropriate dose and duration of use of the drugs used in the treatment of sarcoidosis. Corticosteroids are the first-line and most commonly used treatment agents. In pulmonary involvement, more than $70 \%$ of patients respond with clinical and radiological response to corticosteroid therapy. However, it has been reported that $25-50 \%$ recurrence may occur in corticosteroid dose reduction or discontinuation (11). Treatment can be started with prednisolone 20-40 mg daily (12). Although doses above $20 \mathrm{mg}$ per day are generally not required in patients with pulmonary involvement, the daily requirement for prednisolone dose may exceed $20 \mathrm{mg}$ in cardiac and neurological involvement. In the follow-up, it should be aimed to reduce to the lowest dose of corticosteroid to control symptoms. The recommended corticosteroid treatment duration and dose reduction schemes are different. While Huninghake et al. (21) recommend that the corticosteroid dose be reduced and discontinued within 6 months after the start of treatment, Winterbauer et al. (22) recommend that the treatment be continued for at least 1 year against the risk of relapse. Second-line drugs may be used in patients with uncontrolled disease activity and symptoms despite corticosteroid treatment, with exacerbation following reduction of corticosteroid dose and with prominent side effects due to corticosteroid treatment. These drugs include chloroquine, hydroxychloroquine, methotrexate, azathioprine, leflunomide, mycophenolate mofetil, cyclosporine, pentoxifylline and minocycline. Cyclophosphamide, anti-Tumor necrosis factor agents, rituximab and thalidomide have also been reported in treatment-resistant and severe cases (23). The treatment of our case was $20 \mathrm{mg}$ oral prednisone. At the end of the second month, her cavitary lesion and complaints regressed.

\section{Conclusion}

Sarcoidosis was diagnosed in a young female patient who had a history of tuberculosis contact and cavitary lesion in our country where tuberculosis was endemic, and clinical and radiological response to steroid treatment was observed in a short time. We presented our case 
of cavitary sarcoidosis because it is rare and there is no case report and/ or series of cavitary sarcoidosis cases in our literature. We believe that we need larger case series on sarcoidosis.

Informed Consent: Informed consent was obtained from the patient.

Peer-review: Externally peer-reviewed.

Author Contributions: Concept - F.E.G., D.T.; Design - M.A.Ö.; Supervision - F.E.G.; Resources - B.Z.Y.; Materials - D.T.; Data Collection and/or Processing - F.E.G., D.T.; Analysis and/ or Interpretation - D.T., M.A.Ö.; Literature Search - F.E.G.; Writing Manuscript - F.E.G.,; Critical Review L.C., M.A.Ö.

Conflict of Interest: No conflict of interest was declared by the authors.

Financial Disclosure: The authors declared that this study received no financial support.

\section{References}

1. Fraser GF. Diagnosis of Disease of the Chest, Fourth Edition, Philadelphia: W.B.Saunders Company 1999; 3(41):1533-83.

2. Sandhu M, Sodhi K, Kalra N, Saxena AK, Kaza RK. Large primary sarcoid cavity: an extremely rare presentation of sarcoidosis. Indian J Chest Dis Allied Sci 2007; 49: 229-31.

3. Criado E, Sánchez M, Ramírez J, Arhuis P, de Caralt TM, Perea RJ, et al. Pulmonary sarcoidosis: Typical anf atypical manifestations at high-resolution CT with pathologic correlation. RadioGraphics 2010; 30: 1567-86.

4. Rohatgi PK, Schwab LE. Primary acute pulmonary cavitation in sarcoidosis. AJR Am J Roentgenol 1980; 134: 1199-1203.

5. Mayock RL, Bertrand P, Morrison CE, Scott JH. Manifestations of sarcoidosis: analysis of 145 patients, with a review of nine series selected from the literature. The American Journal of Medicine Am J Med 1963; 35: 67-89.

6. Rockoff SD, Rohatgi PK. Unusual manifestations of thoracic sarcoidosis. AJR Am J Roentgenol 1985; 144: 513-28.

7. Cox CE, Davis-Allen A, Judson MA. Sarcoidosis. Med Clin North Am 2005; 89: 817-28.

8. Iannuzzi MC, Fontana JR. Sarcoidosis: clinical presentation, immunopathogenesis, and therapeutics, JAMA 2011; 305: 391-9.
9. Musellim B, Kumbasar OO, Ongen G, Cetinkaya E, Turker H, Uzaslan E, et al Epidemiological features of Turkish patients with sarcoidosis. Respir Med 2009; 103: 907-12

10. Baughman RP. Pulmonary sarcoidosis. Clin Chest Med 2004; 25: 521-30.

11. West SG. Sarcoidosis. In: Hochberg MC, Silman AJ, Smolen JS, Weinblatt ME, editors. Rheumatology. Edinburgh: Mosby; 2011; 1641-51.

12. Statement on sarcoidosis. Joint Statement of the American Thoracic Society (ATS), the European Respiratory Society (ERS) and the World Association of Sarcoidosis and Other Granulomatous Disorders (WASOG) adopted by the ATS Board of Directors and by the ERS Executive Committee. Am J Respir Crit Care Med 1999; 160: 736-55.

13. Kıyan E. Sarkoidozda ekstrapulmoner tutulum. Türkiye Klinikleri Göğüs Hastalıkları Özel Sayısı 2009; 2: 72-81.

14. Lachkar S, Dominique S, Thiberville L, Nouvet G, Genevois A. Aspergillosis and sarcoidosis. Rev Mal Respir 2007; 24: 943-53.

15. Tomlinson JR, Sahn SA. Aspergilloma in sarcoid and tuberculosis. Chest 1987; 92: 505-8.

16. Wollschlager C, Khan F. Aspergillomas complicating sarcoidosis. A prospective study in 100 patients. Chest 1984; 86: 585-8.

17. Freundlich IM, Libshitz HI, Glassman LM, Israel HL. Sarcoidosis. Typical and atypical thoracic manifestations and complications. Clinical Radiology 1970; 21: $376-83$.

18. Ozseker ZF, Yilmaz A, Bayramgurler B, Guneylioglu D. Cavitary sarcoidosis: analysis of two cases. Respirology 2002; 7: 289-91.

19. Froudarakis ME, Bouros D, Voloudaki A, Papiris S, Kottakis Y, Constantopoulos $\mathrm{SH}$, Siafakas NM. Pneumothorax as a first manifestation of sarcoidosis. Chest 1997; 112: 278-80.

20. Lemay V, Carette MF, Parrot A, Bazelly B, Grivaux M, Milleron B. Hemoptysis in sarcoidosis. Apropos of 6 cases including 4 with fatal outcome. Rev Pneumol Clin 1995; 51: 61-70.

21. Hunninghake GW, Gilbert S, Pueringer R, Dayton C, Floerchinger C, Helmers $\mathrm{R}$, et al. Outcome of the treatment for sarcoidosis. Am J Respir Crit Care Med 1994; 149: 893-8.

22. Winterbauer RH, Kirtland SH, Corley DE. Treatment with corticosteroids. Clin Chest Med 1997; 18: 843-51.

23. Lazar CA, Culver DA. Treatment of sarcoidosis. Semin Respir Crit Care Med 2010; 31: 501-18. 